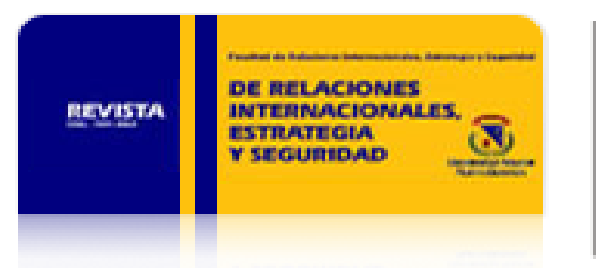

Revista de Relaciones Internacionales, Estrategia y Seguridad

ISSN: 1909-3063

cinuv.relinternal@unimilitar.edu.co

Universidad Militar Nueva Granada

Colombia

Cancelado, Henry

EL FINAL DEL CONCIERTO EUROPEO: CONFLUENCIA DE POLÍTICA Y ECONOMÍA

Revista de Relaciones Internacionales, Estrategia y Seguridad, vol. 4, núm. 1, enero-junio, 2009, pp.

55-67

Universidad Militar Nueva Granada

Bogotá, Colombia

Disponible en: http://www.redalyc.org/articulo.oa?id=92712970004

- Cómo citar el artículo

Número completo

- Más información del artículo

Página de la revista en redalyc.org

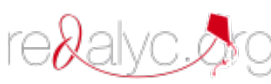

Sistema de Información Científica

Red de Revistas Científicas de América Latina, el Caribe, España y Portugal

Proyecto académico sin fines de lucro, desarrollado bajo la iniciativa de acceso abierto 
rev.relac.int.estrateg.segur.4(1):55-67,2009

\title{
EL finAl del CONCIERTO EUROPEO: CONFLUENCIA DE POLÍTICA Y ECONOMÍA
}

\author{
Henry Cancelado*
}

\section{RESUMEN}

Durante el siglo XIX, los países estuvieron en un constante conflicto por la organización del poder político, militar y económico del sistema europeo. Una vez el Congreso de Viena de 1814, se reunió para reorganizar las fronteras y reestablecer un orden dentro del viejo continente, los enfrentamientos entre un orden internacional -basado en una forma de producción y en unas ideas políticas novedosas y un régimen antiguo que deseaba mantener las estructuras anteriores tanto de orden económico como de orden político-, condensaron todos los conflictos de diferente naturaleza, que se dieron a lo largo de todo el siglo antepasado. Así, la aglutinación de las diferencias y la creciente acumulación de poderes militares, políticos y económicos, de las potencias europeas, Ilevaron a que las tendencias del siglo XIX explotaran en una gran conflagración que permitió el nacimiento de la estructura de poderes del siglo XX y marcó el final de la era exclusivamente europea dentro del sistema internacional.

\footnotetext{
* Politólogo y Magíster en Análisis de Problemas Contemporáneos. Director Centro de Investigación Facultad de Relaciones Internacionales, Estrategia y Seguridad. hcancelado@gmail.com
} 


\title{
Palabras clave
}

Europa, capitalismo, conflicto, imperialismo.

\begin{abstract}
Along the $19^{\text {th }}$ Century, the countries were in an everlasting conflict because of the organization of the political, military and economical power of the European system. Once the Congress of Vienna in 1814 was met to reorganize the borders and to reestablish an order inside the old continent, the confrontations between a new international order, based in a manner of production and in novel political ideas, and an antique regime which wanted to maintain former structures in the economical and political order; condensed all the conflicts, from different nature, that were presented along the $19^{\text {th }}$ century. In that sense, the condensation of the differences and the growing accumulation of military, political and economical powers, of the European powers; caused that the century exploited in a huge conflagration which allowed a new birth of the powers structure in the $20^{\text {th }}$ century and pointed the end of the era of the exclusive European power in the international system.
\end{abstract}

\section{Key Words}

Europe, capitalism, conflict, imperialism.

\section{INTRODUCCIÓN}

Cuando los revolucionarios franceses destruyeron el régimen monárquico, jamás pensaron que su aventura histórica llevaría al sistema internacional a conocer una serie de nuevos conceptos políticos que transformarían la historia de las ideas políticas y la historia mundial desde ese momento. Cuando la burguesía inglesa desarrolló a plenitud su capacidad económica y acorraló a la nobleza tradicional, asumió que una nueva era de prosperidad en el sistema internacional había comenzado. Cuando el nacionalismo alemán organizó los reinos germanos y desarrolló su sistema económico, entendió que un gran poder central había surgido. Lo que hay en común entre las tres empresas políticas y económicas es que cada una, desde sus propias variables y contextos, coadyuvó a que Europa llegara a la expresión máxima de su poder, a prepararla para que dicho poder se viera expandido por el sistema internacional, pero a la vez difuminado y cedido a otras potencias no europeas, potencias que dominarían el siglo XX.

El poder europeo, que se había difundido durante varios siglos desde la cuna mediterránea hasta los extremos de Asia y América, jamás pensó que pudiera enfrentarse a una lucha interna que amenazara su preeminencia en el sistema internacional. Los conflictos religiosos del siglo XVI y las revoluciones que desarticularon el imperio español en sus territorios europeos no pudieron garantizar el establecimiento de un orden que controlara los desmanes de los choques sociales y abrieron un vacío de poder. Por el contrario, ayudaron a soportar, mantener y aumentar las bases ideológicas que explotaron en grandes conflictos europeos.

EL FINAL DEL CONGERTO EUROPEO: CONFLUENCIA DE POLÍTICAYECONOMÍA 
Este artículo tiene como objetivo analizar las tendencias económicas y políticas que aumentaron las contradicciones intraeuropeas hasta llegar a las guerras mundiales. Es necesario hacer un seguimiento histórico comparado, basado esencialmente en Gran Bretaña y Alemania, aunque eventualmente se analicen otros países para lograr variables subsidiarias al análisis. De fondo subyace la idea de los escépticos globalistas ${ }^{2}$ para quienes los fenómenos de crecimiento económico han existido siempre $y$, por consiguiente, es difícil determinar que existe una globalización a partir de ciertos hechos exclusivos del siglo XX. Para completar el estudio, es necesario asumir como tesis que la expansión económica de tipo imperialista y el exacerbado nacionalismo llevaron a grandes conflictos a comienzos del siglo XX. Como consecuencia de dichas contradicciones, Europa, como continente, perdió su papel preponderante y cedió su poder a nuevas potencias extraeuropeas en el sistema internacional.

En la primera parte, se analizará el desarrollo de la globalización como fenómeno económico para demostrar que no es una tendencia histórica novedosa, sino una tendencia constante dentro de la estructura del sistema internacional. Sin embargo, hay que concederle a los transformacionalistas ${ }^{3}$ que existen nuevas variables dentro de la globalización. El asunto es si son nuevas expresiones de lo mismo o si son expresiones de algo totalmente novedoso.

En seguida, se estudiará el fenómeno de la expansión imperialista europea de finales del siglo XIX y se articularán las variables economía y nacionalismo. Así, es posible demostrar más directamente la relación entre conflicto y economía, no porque el nacionalismo sea per se conflictivo, sino porque se convierte en un gran catalizador de radicalismos que no caben en un fenómeno de globalización económica, como el vivido a finales del siglo XIX. En este mismo aparte, se hará la comparación entre las potencias europeas y se analizará su devenir histórico hasta la primera conflagración mundial.

Por último, se concluirá, sustentado en las variables de análisis, que la economía, mezclada con la política y, en este caso, con la expansión imperialista, generó una serie de dinámicas que enfrentaron a las potencias de la época, pero con el resultado de que el poder del sistema internacional fue concedido a potencias que lograron aglutinar mayor poder y mayor coherencia en sus proyectos desarrollistas y expansionistas.

\section{LA GLOBALIZACIÓN COMO PROCESO CONSTANTE}

Dentro de la estructura de los procesos que dan como resultantes los fenómenos del sistema internacional, se encuentra la tendencia de la globalización. Ésta, a partir de la organización de ciertos procesos estructurales del sistema internacional, va derivando algunas variables adyacentes que, en su confrontación, van generando nuevos fenómenos que afectan al mismo sistema internacional.

${ }^{2}$ Cfr. HELD, 2002.

${ }^{3}$ Ibíd. Introducción. 
Analizar la globalización implica entender que no es un fenómeno reciente. Por el contrario, depende de determinantes estructurales más profundos en el sistema internacional. Si ha de suponerse como un fenómeno exclusivamente económico, no resulta ser un fenómeno totalmente novedoso. En los siglos XX y XXI, se da una economía integrada basada en una compresión del espacio y del tiempo, como resultado de la tecnología actual, y que produce un aumento en la velocidad de los flujos comerciales y económicos. Eso no significa una mayor o menor conexión que en otros momentos del sistema internacional, sino que la repercusión y la trayectoria como dimensiones de análisis de esos flujos ${ }^{4}$ permiten observar que el fenómeno, como tal, ha tenido épocas de mayor esplendor. Por ejemplo, a finales del siglo XIX en la creación y difusión de los imperialismos europeos, tanto continentales como de ultramar $^{5}$.

El desarrollo del sistema económico actual depende de unas variables definitorias que se encuentran a lo largo de la historia. Para entender el sistema actual con su ética, política y economía, es necesario hacer una arqueología del sistema internacional y determinar las variables que han ayudado a la expansión del sistema liberal contemporáneo. Entender que los fenómenos como la globalización dependen no solamente de un hecho específico, sino de la inextricable unión de una serie de fenómenos, permite ver más fácilmente que la globalización económica, por un lado, es una expresión más de un fenómeno amplio de interacción mundial y, por otro lado, es la última expresión de un sistema económico que empezó horadando el orden feudal medieval y que explotó con fuerza a finales del siglo XIX.

La intensidad de la interdependencia del sistema internacional desde 1890 muestra que el fenómeno "globalizatorio" ya había empezado antes del emplazamiento del capitalismo financiero del siglo XX, o de los grandes desarrollos tecnológicos en comunicaciones. La Guerra Fría, por el contrario, congeló ciertos flujos y dividió el mundo, fraccionando las comunicaciones que ya se tenían; por ejemplo, las relaciones Rusia-Europa Occidental se rompieron y el aislamiento de ciertos focos del Tercer Mundo los hizo campo de batalla ideológico, antes que puntos de desarrollo internacional.

De esta manera, es claro que asistimos más a una internacionalización constante de un modelo, de un sistema homogenizante a nivel axiológico, antes que a un desarrollo "global» del mundo. De todas formas, el Estado mantiene el control, tal y como lo ha mantenido desde su origen. La actual crisis lo demuestra pues con el fracaso del mercado liberal y su especulación, el Estado retoma el poder frente a la economía.

Esta dinámica de control del Estado frente a la esfera económica potenció el imperialismo del siglo XIX y su expansión por todo el globo. El choque de las dinámicas políticas de la Europa de comienzos del siglo XX hizo que la economía se complementara con las decisiones y manejos políticos.

${ }^{4}$ Íbid, pp. XLV - XLVII.

${ }^{5}$ Cfr. Arendt, 2007. Cap. 8.

EL FINAL DEL CONCIERTO EUROPEO: CONFLUENCIA DE POĹTICA YECONOMÍA 
Como consecuencia, la expansión y afirmación nacionalista devino en una confrontación de intereses políticos y económicos de expansión y de choque de esferas de influencia. Es decir, cuando en el curso de la afirmación nacional capitalista de un Estado se encontraba con el proceso productivo, comercial y político con otro, se daba el conflicto internacional. He aquí la razón por la cual solamente dos de los países extraeuropeos -Estados Unidos y Japón-, que habían logrado gran desarrollo económico e industrial, se inmiscuyen en las dos guerras mundiales. El caso Rusia no es de expansión capitalista, pero sí de desarrollo industrial e imperialismo estatal, elementos básicos del conflicto.

De tal manera, gracias a la multiplicidad en la causalidad de la globalización, puede determinarse un doble conflicto. En primer lugar, por la expansión, incluso invadiendo y doblegando las resistencias nacionales que puedan generarse. En segundo lugar, la exacerbación ideológica de un discurso que se piensa como totalizante en el sistema internacional, el cual genera cierta resistencia frente a la imposición. Tal es el caso del discurso nazi frente al capitalismo, que se veía como decadente. Sin embargo, bajo algunos elementos primitivos del discurso liberal de nación se expandió el Tercer Reich, afirmando un Estado y un sistema económico frente a los demás. A la larga, el modo de producción y la dinámica política alemana buscaba enfrentarse al modo de producción y a la dinámica política británica. Era su única forma de sobrevivir como el proyecto hegemónico que pretendían los nazis.

\section{EL PODER EUROPEO: EXPANSIÓN Y DESARROLLO}

A partir del siglo XVI, el continente europeo se levantó como un poder en expansión dentro del sistema internacional, todas las costas del mundo empiezan a divisar sus barcos militares y comerciales. Desde la expansión de España y Portugal hasta el establecimiento del poder británico, Europa conoció todo el globo, explotó a nivel mercantilista y desarrolló un poderío de tipo imperial caracterizado por el establecimiento de colonias y, por otro lado, el posicionamiento de una superioridad militar y política, en todos aquellos rincones a los que llegaba.

Sin embargo, es necesario entender que dicha expansión tiene una doble característica. Por un lado, la expansión inicial de las potencias de la Península Ibérica que logró configurar un orden colonial que tenía como centro al continente americano. Así, organizó una dependencia casi exclusiva a nivel económico y le dio al Atlántico el protagonismo que en antaño había tenido el Mediterráneo.

El auge del poder comercial, gracias a las nuevas colonias, llevó a Europa a sobreponerse a los vecinos como potenciales enemigos y, a su vez, le permitió convertirse en un nuevo centro comercial del sistema internacional, desplazando a Rusia y al Imperio Otomano, cada uno como pasos obligados de la producción del Imperio Chino y en general de Asia ${ }^{6}$. Según Paul Kennedy ${ }^{7}$, «todo

${ }^{6}$ Cfr. Pomeranz, 2000. Cap. 3 y 4.

${ }^{7}$ Kennedy, 1992. P. 62. 
esto condujo a un crecimiento acelerado del comercio trasatlántico, cuyo volumen aumentó ocho veces entre 1510 y 1550 y otras tres veces entre 1550 y 1610». Así las cosas, la fuerza que se empezaba a alcanzar hacían posible el fortalecimiento de los reinos a nivel interno, pero mantenía un ambiente de conflicto en toda Europa.

Por otro lado, la expansión de otras potencias como Inglaterra y Francia intentó, de la misma manera y teniendo las mismas características de colonización, establecer un imperio trasatlántico. Sin embargo, el poder de España se volvió casi absoluto en las rutas comerciales marítimas, el poder ibérico, no pudo ser superado, ni en el continente, ni en el océano. En este caso, Inglaterra, Francia y el resto de potencias que no participaron de manera exitosa en esa gran expansión inicial, debieron esperar hasta el siglo XIX y principios del siglo XX para poder llegar al máximo de su poder e influencia en el sistema internacional.

\subsection{El concierto europeo, el fin de la Edad Media y el Imperio Español}

La configuración de un concierto europeo en el continente se dio debido a la fortaleza de actores poderosos y de ciudades ricas, pero vulnerables. Es el caso de Venecia, que desde finales de la Edad Media logró establecer una diplomacia comercial que le permitió entenderse con los otomanos y con los europeos, pero sin comprometerse políticamente con ninguno de los dos lados.

La eclosión de riqueza desmesurada y de una vasta capacidad militar de algunas potencias obligó a desarrollar una capacidad diplomática de aquellas potencias menos fuertes, pero bastante atractivas para los poderes vecinos. Esta situación interna generó grandes lazos al interior de Europa, ya fuese por medio de la unión de casas reales o por medio del comercio. Los conflictos ya se empezaban a entender desde el campo de las alianzas y no tanto desde la lucha de reinos relativamente pequeños por poderes medianos.

Ambas características -el concierto europeo y la expansión ultramar- llevaron no solamente la institucionalidad y el comercio europeo por todo el sistema internacional, sino también la cultura europea hacia los rincones más alejados del globo. De esta manera, la Europa cristiana había logrado establecer unos principios civilizatorios demasiado amplios y profundos a nivel geográfico y social. La ventaja que logró fue poder tener aliados y puntos comerciales en todos los continentes y a su vez centralizar su riqueza y repartirla en centro de poder pequeños.

La producción del sistema internacional benefició en algún momento a las metrópolis en el viejo continente, y a cambio el sistema recibió el establecimiento de una cultura y la dependencia de los cambios estructurales al interior de Europa, por ejemplo, de las Revoluciones Francesa e Industrial. Tal influencia, permitió a los nuevos actores participar del sistema internacional, hablando el mismo lenguaje que el centro de poder, lenguaje que se logra o por medio de la imposición o por medio de la asimilación de los valores repartidos. Tal es el caso de dos actores que irrumpen con fuerza a finales del siglo XIX: Estados Unidos y Japón.

EL FINAL DEL CONGIERTO EUROPEO: CONFLUENCAA DE POLÍTICA Y ECONOMÍA 
El concierto europeo logra, a pesar de las luchas internas, desarrollar paralelamente a su expansión los reinos como institución organizativa de la política interna, lo que dio paso a algunos Estados absolutistas inicialmente y posteriormente al Estado nación. El Estado territorial y soberano le da fuerza a Europa como continente, pero a su vez, la dinámica política y económica europea demorará en darle una organización realmente democrática al mismo.

A partir del siglo XIX, la concentración del poder militar, político y económico en un espacio tan pequeño es desafiante para ese momento histórico. En el sentido antiguo, los grandes imperios, incluso en la concepción española, se anexaban directamente territorios en torno a una metrópoli, lo que era fundamental para la organización política y económica del Imperio junto con el establecimiento de un cuerpo jurídico que permitiera el dominio legalizado. Sin embargo, esta nueva forma imperial era diferente. Su punto de éxito fue haber tomado como base de su expansión los elementos difusos del capitalismo de la época, la creación de excesiva riqueza y la aparición de los nacionalismos europeos, basados en la xenofobia y en la radicalización de los discursos políticos.

La estructuración del desarrollo económico y de la identidad de nación que desarrollaron tanto Alemania como Inglaterra, les dio una proyección particular en el sistema internacional. Una vez se unifica Alemania a finales del siglo XIX, las fuerzas políticas y militares del continente encuentran una gran contendor que se establece en el centro de Europa, naciendo como un posible contendor de Francia y Rusia, pero, a su vez, proyectándose como el hegemón del poder continental. La unificación trajo consigo la proyección del poder de la nación alemana, en la cual la mezcla entre los Junkers ${ }^{8}$ y el pueblo originó un sustrato nacionalista sobre el cual se montaron las tesis de desarrollo y expansión de Alemania.

Por su parte, la Europa insular, es decir Inglaterra, conformado como el Imperio Británico, gozó siempre de un aislamiento de los asuntos continentales, lo que le permitió abrirse a otros mercados. Observar la situación desde la isla fue la mejor estrategia histórica que Gran Bretaña utilizó para dedicarse mejor al comercio mundial y a sus inversiones de ultramar que a los asuntos de la delicada y de por sí cargada política europea. Ese manejo y dominio del continente fue un aspecto reservado para Alemania. De esta manera, el imperio constituido básicamente por Inglaterra logró desplegar toda su capacidad económica y burocrática alrededor del mundo de finales del siglo XIX. Los dominios, desde India hasta Egipto, eran muestra del poderío que poseía. Como consecuencia, logró crear un polo de poder que lo posicionaría como el país de mayor proyección internacional para ese momento.

Cuando en el crecimiento de ambas potencias se encuentran en la naturaleza de su desarrollo y expansión, empiezan los problemas de cruce de poderes, que van a ser solucionados por medio de la guerra. Los procesos que traía consigo el sistema internacional desde el siglo XIX van a terminar de manera definitiva al final de la Segunda Guerra Mundial, cuando el poder internacional se

${ }^{8}$ Grandes terratenientes germanos que se asumían como la aristocracia. 
expande por el resto de países del sistema y se desconcentra de la estructura europea. A su vez, ciertas potencias crecen paralelas y asumen ese poder en la segunda mitad del siglo XX, articulando el desarrollo económico -capitalista o no- con una identidad nacional profunda que dio la idea de fortaleza y dominio en el sistema internacional.

\subsubsection{El sistema no europeo}

A pesar de aquella difusión, hubo escenarios geográficos que quedaron por fuera de la lucha central de poderes. Por un lado, las jóvenes naciones decimonónicas allende el Océano Atlántico miraban expectantes el devenir europeo. En el sur del continente americano las antiguas colonias españolas se sumieron en sí mismas y entre ellas se enfrentaron en grandes conflictos que no permitieron el desarrollo y cohesión de una Latinoamérica que pudiera jugar papeles determinantes en el sistema internacional. América Latina se posicionaba en su papel de espectadora de la historia universal, con grandes traumatismos internos. Las guerras en todo el continente dejaron naciones empobrecidas y eclipsaron cualquier atisbo de poder latino que pudiera proyectarse por medio del comercio mundial o a través de un poderío militar y político que estableciera las bases de naciones modernas. De tal manera, se entiende la expulsión de Latinoamérica de la lucha de poderes en el Sistema Internacional a lo largo del siglo XIX y principios del XX.

Por otro lado, en el norte del continente americano los conflictos que se llevaron a cabo ${ }^{9}$ fueron consecuencia de la pretensión de los Estados Unidos de expandir su área de influencia y de llevar a plenitud la doctrina de dominio continental ${ }^{10}$. En este proceso se encontró con el único país que pudiera, a nivel continental, considerarse una amenaza a su poder, ya que la capacidad geográfica que tenía México sobrepasaba con creces el poderío de los Estados de la unión. Prueba de tal amenaza fue la capacidad de México para enfrentar un intento de invasión europea.

La operación de Francia sobre México en el siglo XIX, si bien puso de relieve la capacidad de las potencias europeas para lograr grandes operaciones de corte imperial en territorios de ultramar, manifestó la falta de estimación de la capacidad de la nación mexicana, lo que se consideró una falla de análisis bélico para emprender la invasión. El Segundo Imperio francés fue derrotado y se convirtió en una de las naciones imperiales vencidas para ese momento en ultramar. Tal acontecimiento selló el destino de Francia como potencia de segunda en el juego europeo, abriéndole paso a dos grandes con los que se va a medir como aliado y enemigo: Inglaterra y Alemania.

A su vez, México, al perder casi la mitad de su territorio en la guerra méxico-americana, se introduce en el proceso descrito de las naciones latinoamericanas. En consecuencia, el único país extraeuropeo con vocación expansiva de inevitable confrontación, que podía llegar con poder establecido y capacidad económica para influenciar al concierto europeo, era Estados Unidos. México quedó anulado por éste y el resto de Latinoamérica se eliminó en sus propias dinámicas.

\footnotetext{
${ }^{9}$ Recordar la guerra méxico-americana y la guerra civil estadounidense de 1860.

${ }^{10}$ Doctrina Monroe: América para los americanos.

EL FINAL DEL CONGIERTO EUROPEO: CONFLUENCIA DE POLÍTICA Y ECONOMÍA
} 


\subsection{La condensación del conflicto}

En el momento en que el Imperio Británico toma una forma global, a partir de la conquista de India en 1773, empezó separarse del colonialismo europeo que habían usado los imperios hasta ese momento y estableció una estructura imperial de corte totalmente económico y de expansión del capitalismo y de la tecnología, resultantes de la Revolución Industrial. Para este momento, una potencia adyacente, Alemania, surgió como poder dentro del sistema europeo. Era inevitable que a principios del siglo XX apareciera el conflicto de la manera en la que apareció.

Varios determinantes llevan a esta deducción: la destrucción de la idea del Estado-nación sometido a la ley republicana y doblegado más bien a las necesidades de una nación amorfa y mixta, creada por residuos sociales de la gran expansión económica ${ }^{11}$. Otro elemento es la expansión del imperialismo continental entre los sectores residuales de la sociedad y con grandes ejércitos que empiezan a armarse para defenderse o para expandir la zona de influencia. En tercer lugar, la creación de relatos nacionalistas extremos como el pangermanismo o el paneslavismo, que no pueden compartir espacio geopolítico con otros proyectos subyacentes como la expansión imperial británica.

La unión entre la economía y la política europea de finales del siglo antepasado estuvo reforzada por la creación de grandes cuerpos de fuerzas militares y su expansión por la Europa continental. Tal y como lo muestra Kennedy respecto a la guerra Franco-Prusiana: «El triunfo de Prusia-Alemania fue, a todas luces, un triunfo de su sistema militar, pero (...) el sistema militar de una nación no es una parte independiente del sistema social, sino un aspecto de él de su integridad ${ }^{12}$. Es decir, dentro del corazón de los Estados se dio un nacionalismo y una expansión económica acompañada de sistemas de ataque y defensa más sofisticados. Esta escalada va a terminar en 1945.

La guerra mundial logró unificar al sistema internacional en torno a un solo suceso mundial, cosa nunca antes vista, ya que tanto el centro de poder como las periferias y los actores externos se vieron involucrados en el enfrentamiento de manera directa o indirecta. Dentro del choque, el sistema se ideologizó y giró en torno a tres variables axiológicas: la libertad (liberalismo), la igualdad (I socialismo) y la superioridad (fascismo). Las tres son radicales, pero con matices diferentes. El nacionalismo fascista y el pretendido supranacionalismo socialista van a enfrentarse al radicalismo libertario de la democracia capitalista de las potencias occidentales. Estructura que al final de la guerra va a definir los nuevos poderes del sistema internacional.

El conflicto se origina exactamente en el momento en el que los Estados se «chocan» en su proceso expansionista. Sin embargo, es necesario precisar que dicho encuentro no se refiere necesariamente a un encuentro físico en una zona de influencia por parte de agentes estatales; dicho encuentro se refiere también a la posible conformación de satélites y, por supuesto, a la lucha por los mercados a los que se apunta en dicho proceso.

\footnotetext{
${ }_{11}$ Op. Cit., Arendt. Cap 7.

${ }^{12}$ Op cit, Kennedy. P. 304.
} 


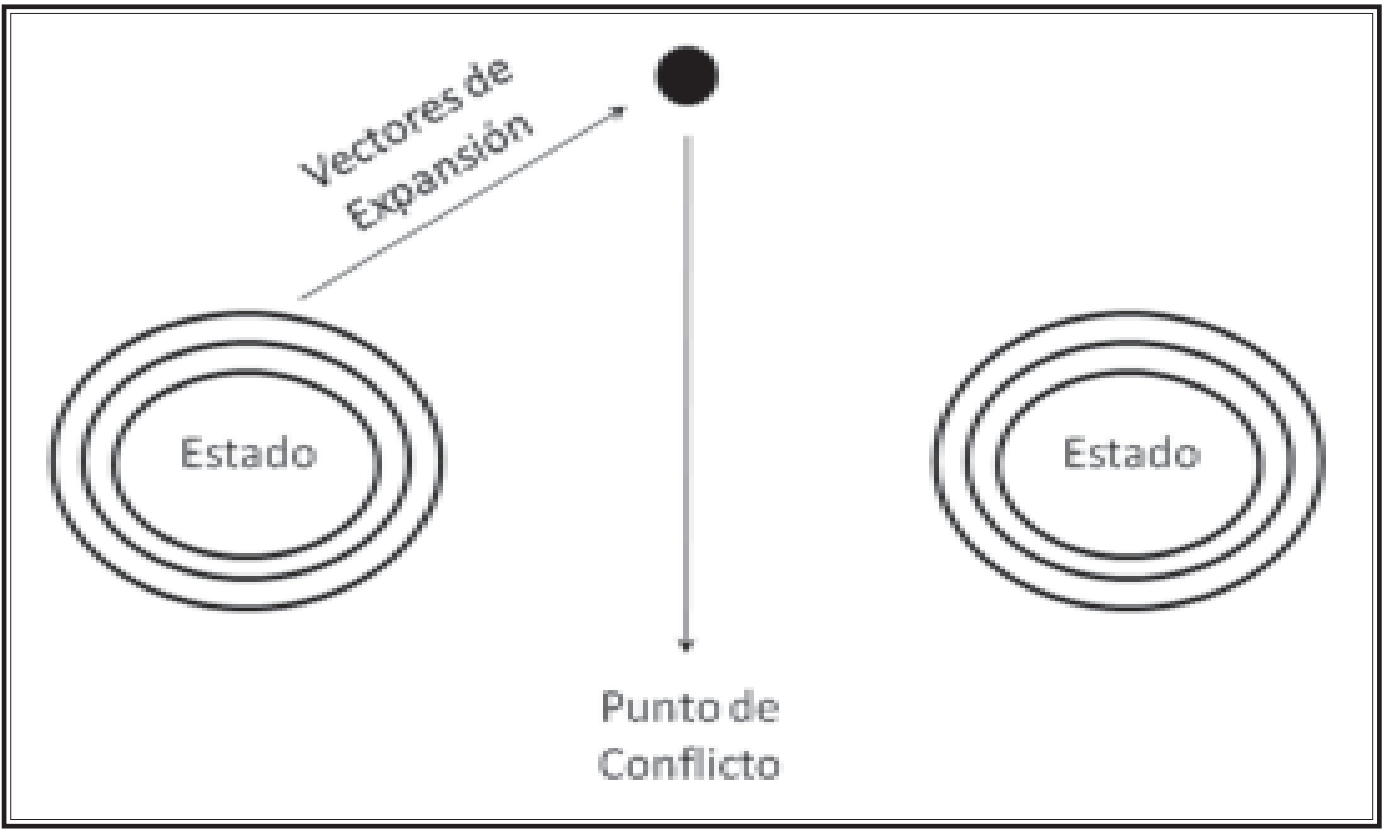

Figura 1. Punto de expansión y de conflicto

\subsection{Las guerras mundiales y el nuevo orden}

La internacionalización desde América hasta Japón de un sistema de valores para el sistema internacional -es decir, el capitalismo liberal y la industrialización- dio como resultado demasiadas potencias en un escenario complejo y altamente volátil. Sin embargo, el punto culmen se dio solamente cuando la radicalización del nacionalismo se encontró de frente con la posibilidad de desarrollo exagerado. Es decir, cuando para los la década de 1930 Alemania había superado su crisis posguerra y empezaba a generar factores adicionales de desarrollo económico, los cuales se enfocaron directamente a la creación de industria pesada y militar, además de las inversiones en infraestructu$\mathrm{ra}^{13}$. La expansión alemana de tipo imperial suplió ambas necesidades de la economía para ese momento; logró romper la ola de aislacionismo y proteccionismo al capital; estimuló el desarrollo industrial por medio de la industria militar; y desarrolló nuevas tecnologías, aumentando la capacidad de comunicaciones del sistema intraeuropeo. Es así como Wilhelmy dice: «Mediante una serie de golpes espectaculares, Hitler pudo romper con las restricciones de Versalles y Locarno, rearmar a Alemania, recuperar territorios perdidos o en discusión, anexarse a Austria y Checoslovaquia» ${ }^{14}$. Sin embargo, a pesar de los cálculos estratégicos y de la gran capacidad militar, Alemania no contó con que el desarrollo económico estaba desagregado geográficamente y no solamente concentrado

\footnotetext{
${ }^{13}$ Cfr. Kennedy. Pp. 474-490.

${ }^{14}$ Wilhelmy von Wolff, 1988. P. 112.

EL FINAL DEL CONGERTO EUROPEO: CONFLUENCIA DE POLÍTICA YECONOMÍA
} 
en Europa. Además, el desconocimiento de la internacionalización de los procesos dentro del sistema internacional, para ese momento, lo llevó a cometer el error de asumir a Estados Unidos como un enemigo dentro del conflicto.

El problema no fue tanto la enemistad de los estadounidenses, sino la débil capacidad que ya tenía el Eje frente a los Aliados, debilidad que se vio fortificada con la economía norteamericana, la cual reforzó la máquina capitalista británica y la hizo fuerte frente a la economía decadente del Eje para el año. Si bien para 1937 Alemania gastaba el 23,5\% de su renta nacional en defensa frente a un 1,5\% de Estados Unidos, para 1943 los estadounidenses cuadruplicaban la producción militar alemana $^{15}$. Mientras que Inglaterra, a pesar de seguir de segundo en el nivel de producción y gasto de defensa, lentamente fue dejando las grandes operaciones a un esfuerzo conjunto de logística y táctica. Sus fuerzas militares nunca fueron tan grandes ni fuertes como las alemanas, ni siquiera en el momento del imperialismo británico.

El autobloqueo europeo por parte de las acciones expansionistas va a traer como consecuencia la dispersión del poder hacia focos extraeuropeos. Solamente cuando la expansión industrial y la gran capacidad económica europea se vio truncada por ella misma, fue cuando el sistema internacional redefinió sus focos y por medio de la guerra escogió a los polos más adecuados para recomponer la esfera de poder de sí mismo. Esta vez, lejos de Europa y lejos el uno del otro.

A diferencia de los Estados Unidos, la Unión Soviética gozó de un gran proceso de industrialización y desarrollo inicial a partir de la década de decaimiento del capitalismo internacional. En los años 1930, logró fortalecer su proyecto socialista y posicionarse como un foco ideológico de poder. Después de la guerra, una vez la Rusia stalinista se dio cuenta de la posibilidad de expandir a nivel continental su poder, se abrió la puerta de la confrontación ideológica en la posguerra. El emplazamiento de las posiciones aliadas en las costas francesas en 1944 y el avance del Ejército Rojo sobre Europa Oriental eran el principio del fin de la guerra. También era el principio de la nueva estructura del poder internacional, el cual, si bien se iba a establecer de manera ideológica, iba a permitir que cada bloque organizara su propia estructura de subsistemas. El mundo se había vuelto bipolar y el orden europeo se había perdido.

\section{CONCLUSIONES}

La globalización como fenómeno económico está determinada por procesos históricos de internacionalización de tendencias internas, en este caso, la expansión capitalista y los imperialismos europeos. Al observar la estructura de desarrollo histórico europeo, desde el Imperio Español hasta el Tercer Reich, las variables de desarrollo comercial influyeron en la compresión del espacio y el tiempo como variables del desarrollo del sistema internacional. Es así como desde el siglo XVI los

${ }^{15}$ Op. Cit., Kennedy. Pp. 554, 525. 
elementos de homogenización de un sistema a nivel económico se vienen presentando y se expanden por el mundo, dando la sensación de una globalización. Las variables económicas y políticas que se expresan a finales del siglo XIX son la evolución de un sistema precapitalista-colonialista europeo y que se van configurando hasta llegar a un modelo de capitalismo industrial y financiero. En este sentido, el crecimiento del sistema económico decimonónico es un proceso de desarrollo natural e histórico en el sistema internacional.

El desarrollo económico del sistema internacional, cuando llegó a un alto nivel de desarrollo y producción, homogeniza a su alrededor el sistema internacional, pero necesita subsanar las diferencias y los radicalismos que se puedan presentar. En cuanto al fenómeno de la expansión imperialista europea de finales del siglo XIX, la economía y el nacionalismo generan la realidad de unos grandes poderes europeos que se asumen en expansión y dominio del sistema global. El problema es cuando se encuentran los poderes en esa expansión natural. En este punto el conflicto se da exacerbado por el desarrollo de una economía expansiva y de una doctrina ideológica también invasiva. Por consiguiente, el capitalismo es el catalizador de radicalismos que se dieron en el viejo continente.

Las dinámicas de expansión política y económica enfrentaron a las potencias de la época, pero con el resultado de que el poder se anuló al interior del concierto europeo y se le abrió a potencias que lograron aglutinar mayor poder y mayor coherencia en sus proyectos desarrollistas y expansionistas. De tal manera, en un momento determinado se articularon el poder político, el poder económico y los radicalismos ideológicos en un escenario geopolítico reducido que agotó rápidamente sus modelos imperialistas y entró en conflicto a su interior. Este agotamiento de sus modelos e ideologías propias dio paso a un nuevo modelo del sistema internacional. En este momento el sistema multipolar flexible cerró los espacios internacionales y generó un sistema bipolar rígido.

\section{BIBLIOGRAFÍA}

- $\quad$ Amin, S. 2004. «Geopolítica del imperialismo contemporáneo». En Varios, Nueva Hegemonía Mundial. Buenos Aires, Clacso, pp. 73-110.

- $\quad$ Arendt, H. 2007. Los orígenes del totalitarismo. Madrid, Alianza Editorial.

- $\quad$ Baldwin, D. A. 1993. Neoliberalism, Neorealism and World Politics. Neoliberalism Neorealism: Term of the Contemporary Debate. New York, University Press.

- $\quad$ Barbé, E. 1995. Relaciones Internacionales. Madrid. Tecnos.

- $\quad$ Beck, U. 1998. ¿Qué es la globalización? Falacias del globalismo, respuestas a la globalización. BarceIona, Paidós Ibérica.

- $\quad$ Berger, M. y Huntington, S. 2002. Globalizaciones múltiples. Barcelona, Paidós

EL FINAL DEL CONGIERTO EUROPEO: CONFLUENCIA DE POLÍTICA Y ECONOMÍA 
- $\quad$ Braudel, F. 1971. Las civilizaciones actuales. Madrid, Tecnos.

- $\quad$ Del Arenal, C. 1984. Introducción a las Relaciones internacionales. Colección de Ciencias Sociales. Madrid, Tecnos.

- $\quad$ Fazio, H. 2004. «La globalización, una reflexión desde la historia». En Globalización: discursos, imaginarios y realidades. Bogotá, IEPRI.

- $\quad$ Friedman, J. 2001. Identidad cultural y proceso global. Buenos Aires, Amorrotu.

- $\quad$ Held, D. 2002. Transformaciones globales. México, Oxford,

- $\quad$ Huntington, S. 1997. El Choque de las civilizaciones. Barcelona, Paidós.

- $\quad$ Kennedy, P. 1992. Auge y caída de las grandes potencias. Barcelona, Plaza y Janes.

- Macfarlane, A. 1993. La cultura del capitalismo. México, Fondo de Cultura Económica.

- $\quad$ Pearson, F. y Rochester, J. M. 2001. Relaciones Internacionales. Bogotá, Mc Graw Hill.

- $\quad$ Pomeranz, K. 2000. The Great Divergente: China, Europe, and the Making of the Modern World Economy. New Jersey, Princeton University.

- $\quad$ Tomassini, L. 1989. Teoría y práctica de la política internacional. Santiago de Chile, Universidad Católica de Chile.

- $\quad$ Wilhelmy von Wolff, M. 1988. Política internacional: enfoques y realidades. Buenos Aires, Centro Interuniversitario de Desarrollo - Grupo Editor Latinoamericano. 